UNIVERSIDADE DE SÃO PAULO

FACULDADE DE CIENCIAS FARMACEUTICAS

Curso de P6s-Graduação em

Ciência dos Alimentos

Área de Nutrição Experimental

\title{
BIODISPONIBILIDADE DE FERRO EM DIETA REGIONAL DE SÃO PAULO
}

\author{
CÉLIA COLLI
}

Tese para obtenção do título de DOUTOR

Orientador:

Prof. Dr. JOSE CARLOS BARBÉRIO 
Ao Rubens 


\section{AGRADECIMENTOS}

Ao Prof. Dr. José carlos Barbērio pela orientação segura.

Ao Prof. Dr. Franco M. Lajolo pela dedicação e apôio constan tes.

Aos Drs. Flāvio Midio, amigo sempre presente, Primavera Borelli e Jülio Kijner, to Departamento de Anälises clinnicas e Toxicológicas.

Aos Drs. Silvia M. F. Cozzolino e Fernando S. Moreno $e$ as pós-graduandas Lūcia Pedrosa, Renata Cintra e Roseane Porto Dantas, do Laboratōrio de Nutrição.

Ao Sr. Carlos Henrique Mesquita, do IPEN, pela amizade.

A Silvania Neves, zootecnista responsāvel pelo biotério da Faculdade de Ciências Farmacêuticas -USP.

A João da Penha e Sandra Maria M. Nascimento, preciosos cola boradores, funcionārios do Laboratōrio de Nutrição.

A Mirna Greco, estagiāria do Laboratōrio de Nutrição, pela colaboração técnica.

A FINEP e à Associação Brasileira de Indūstrias de Alimentos (ABIA) pelo suporte financeiro. 
Beatriz Cordenusi,

Elisabeth Garcia, Flāvio Finardi Filho,

Heloisa Tavares, Leda Saba, e

Maria Hielena Buazar,

pelo carinho de sempre. 


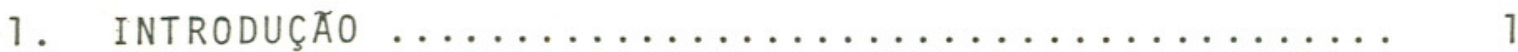

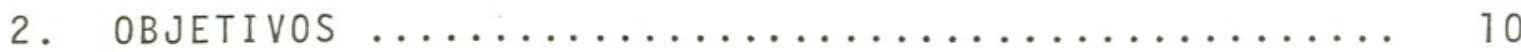

3. MATERIAL E METODOS ...................... 11

3.1. Preparação e anālise das rações ........... 11

3.1.1. Material .................. 11

3.1.1.1. Ração à base de caseîna ......... 11

3.1.1.2. Ração à base de feijão ......... 14

3.1.1.3. Ração à base da dieta regional de São Paulo ..................... 15

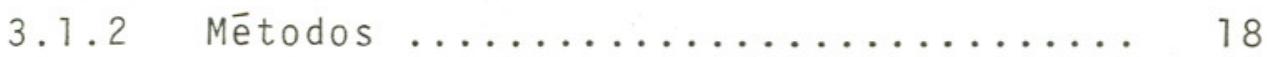

3.1.2.1. Preparação das rações .......... 18

3.1.2.2. Determinação da composição centes $\underline{i}$ mal das rações ................ 19

3.1.2.3. Determinação de minerais ....... 20

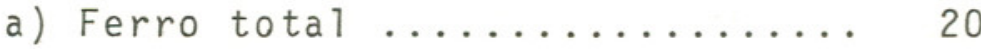

b) Ferro não hemīnico ........ 20

c) Cālcio e fósforo ............ 21

3.2. Repleção de hemoglobina em ratos anēmicos ... 21

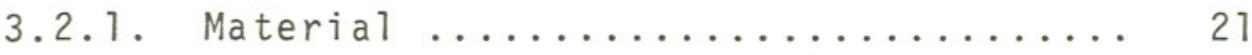

3.2 .1 .1 . Animais .................. 21

3.2.2. Métodos ................... 21

3.2.2.1. Obtenção de ratos anēmicos ...... 21

3.2.2.2. Repleção da hemoglobina ....... 23 
pāg.

3.3. Determinação da porcentagem de ferro dialisā vel das rações em estudos ............... 24

3.3.1. Material ................ 24

3.3.2. Métodos .................. 24

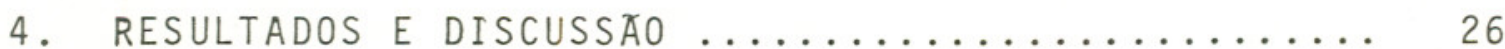

4.1. Composição de dieta regional ........... 26

4.2. Padronização das condições de obtenção de ra

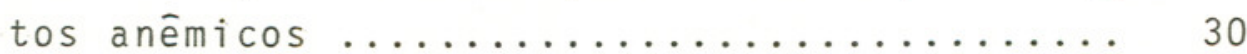

4.3. Valor biológico do ferro em dietas ........ 39

4.4. Determinação do ferro dialisāvel ........ 46

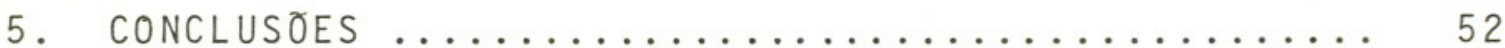

6. REFERENCIAS BIBLIOGRAFICAS .............. 54

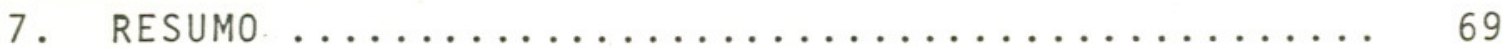

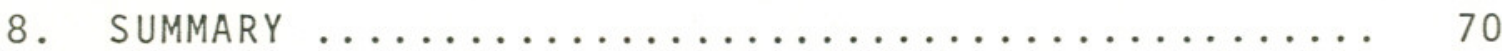




\section{INTRODUÇÃO}

0 ferro, elemento presente em todas as células do organismo e envolvido com um grande nūmero de reações bioquĩmicas, tem uma importância nutricional largamente conhecida(19).

A anemia nutricional é de acordo com a Organização Mun dial de Saūde (OMS) um dos maiores problemas de sāude pública de países em desenvolvimento.

E conceituada como: "a condição na qual a concentra ção de hemoglobina está abaixo do nīvel considerado normal para um dado indivîduo, devido à deficiência de um ou mais dos nutrientes necessários para a hematopoiese; ou alternativamente, como a condição na qual a concentração de hemoglobina se eleva com o aumento de nutriente(s) absorvi do(s)". Sua maior causa è a deficiēncia de ferro.

Os levantamentos da prevaléncia da anemia em uma população, para caracterização dos grupos de risco aos quais dirigir campanhas de suplementação ou fortificação de alimentos são metas a serem cumpridas necessariamente para a resolu ção do problema.

Embora não diretamente letal ao organismo(8), a anemia por deficiência de ferro prejudica grandemente as atividades fundamentais do ser humano, tanto no contexto individual, como no social. 
A relação que existe entre a ocorrēncia de anemia e condições sōcio-econōmicas e culturais de uma população é evị dente.

GRIVETTI $^{(26)}$, em ensaio feito sobre o tema que deno minou Nutrição Cultural aponta a ampla associação entre o tipo de dieta sugerida, o estado nutricional e o comportamento humano.

Assim, quando se pensa na melhoria da qualidade nutricional de uma dieta, deve-se ter em mente que a cultura é considerada o seu maior determinante.

Por outro lado, fatores sōcio-económicos dificultam a possibilidade da escolha adequada de alimentos e estão as sociados a condições higiênico-sanitārias insatisfatōrias.

Essas condições, em sua interação, explicam a eleva da incidéncia de anemia em paisses como o nosso(3)(9)(21)(65) (73)

o ferro, não obstante ser um dos minerais mais abundantes na natureza, tem uma biodisponibilidade geralmente limitada, e espécies superiores frequentemente apresentam esta dos de deficiência do elemento.

o conceito de biodisponibilidade, utilizado inicial mente no campo da farmacologia, aplicável aos estudos na àrea de Nutrição expressa a fração de um nutriente aportado por 
um alimento ou dieta, que è absorvido e metabolizado pelo organismo $(32)$.

O ferro estā presente em todas as cēlulas do orga nismo como parte de metaloproteĩnas, que podem ser classifica das em três grupos (31)(85).

0 primeiro é o de proteĩnas que caracterizam-se por sua habilidade em ligar oxigēnio reversivelmente; a esse grü po pertencem a hemoglobina e a mioglobina. O ferro provenien te dessas duas moléculas corresponde a cerca de 2,5 e $1,5 \mathrm{~g}$ res pectivamente, no homem adulto.

o segundo grupo è o de proteĩnas que formam comple xos reversiveis com o elemento e cuja função principal é de transporte e armazenamento. Assim, o ferro de ferritina e he mossiderina corresponde a $0,5-1,0 \mathrm{~g}$ no homem adulto e menos do que $0,5 \mathrm{~g}$ na mulher adulta. O ferro de transferrina, a prote $\bar{i}$ na de transporte, é cerca de $3 \mathrm{mg}$ em ambos os casos.

Ao terceiro grupo pertencem o extenso nümero de enzimas relacionadas, na maioria dos casos, com reações de óxido-redução e que equivale a um total de 6 a $8 \mathrm{mg}$ do elemento.

o balanço de ferro no organismo é mantido por ajustes fisiológicos dos mecanismos de absorção.

NARASINGA RAO $(50)$, sistematizando as fases de absor ção de ferro, subdividiu-as em três: intra-luminar, mucosa e corpōrea.

A fase intra-luminar em que o alimento é digerido 
por enzimas gāstricas e pancreāticas no lūmen intestinal. E nessa fase que as interações entre o ferro e componentes dos alimentos tem a sua maior influência.

A fase mucosa, que ocorre principalmente no duodeno e que se caracteriza pela retirada, por receptores da cēlula mucosa, do ferro iónico liberado dos alimentos. Esse processo é dependente de energia(37)(68).

$\mathrm{Na}$ ūltima fase, dita corpórea o elemento é retirado pela transferrina e levado pelo sistema circulatōrio, ao fĩgado e tecidos hematopoiéticos.

Consideram-se dois "pools" de ferro no processo de absorção: o ferro hemīnico, que normalmente representa uma parte menor (10-15\% em países desenvolvidos) na ingestão total do elemento, e o ferro não hemínico, na forma de sais $1 i-$ gados ou não a componentes do alimento.

Ferro hemīnico e não hemīnico entram na cēlula mucó sa por diferentes vias. O ferro não hemínico é liberado dos alimentos na forma solúvel e ionizada, ou como sais inorgânicos insolúveis. Considera-se que o ferro na forma solūvel se ja o mais disponível para a absorção.

o ferro hemīnico é absorbido intacto pela cēlula da mucosa. Há evidēncias de que uma heme-oxigenase catalise a quebra do grupo heme absorvido, levando à liberação do ferro $(60)(83)$.

A quantidade de ferro que atravessa a barreira do 
epitēlio gastro-intestinal relaciona-se com o estado nutricio nal em ferro do organismo.

o transporte da mucosa intestinal para o plasma é limitante, e varia inversamente com as alterações no ferro corporal.

0 controle da absorção intestinal do ferro pela mucosa do intestino delgado está estreitamente relacionado com - balanço entre dois compartimentos intra-celulares: a transferrina de transporte e a ferritina, de armazenamento (11)(15) (18) (69)

Em situações de equilībrio fisiolōgico, as necessidades de ferro são determinadas, em sua maior parte, pela quan tidade de ferro perdido pelo organismo. Essas perdas são, em geral, devidas à descamação de superfícies epiteliais, às per das de sangue pelo trato gastro-intestinal e à excreção bi1 iar.

A absorção de ferro não hemínico é muito afetada pe 10 estado nutricional em ferro, o que não é observado com o ferro hemínico abaixo de poucos miligramas por refeição (31) (84).

A biodisponibilidade de ferro é, em primeiro lugar, determindada pela fração do mineral liberada pelo alimento e, em segundo lugar, pela solubilidade, peso molecular e estabilidade dos complexos formados com o ferro liberado.

Fatores como a digestibilidade do alimento, a pre - 
sença de redutores e ligantes e o pH do trato gastro-intestinal, são imediatamente lembradas quando se trata dessa libera ção.

Estes fatores são divididos em fatores facilitado res e fatores inibidores (16)(20).

Entre os chamados fatores facilitadores o ācido ascōrbico e a carne são os mais importantes (16).

STEKEL (77) relata que a absorção de ferro de fortificação em diferentes formulações varia de 3 a $12 \%$ dependendo de seu conteūdo em àcido ascōrbico.

BERNER $^{(7)}$ em revisões sobre os efeitos da proteīna na biodisponibilidade de ferro aponta a importáncia da carne como agente facilitador da absorção pela liberação de peptí deos que formam, com o ferro, complexos solúveis de baixo peso molecular.

Por outro lado, outras proteĩnas, como a caseĩna, a gelatina e a proteîna de soja tem ação contrāria, liberando peptīdeos que formam complexos insolūveis com o elemento.

Entre os fatores inibidores presentes nos alimentos podemos destacar os taninos contidos por exemplo, no chā e no cafē. Moléculas orgānicas, como os oxalatos e os fitatos, tam bēm são considerados inibidores da absorção de ferro(13)(20) (49), embora no caso dos oxalatos a questão ainda não esteja esclarecida $(82)$.

A questão da fibra como fator interferente ainda é 
discutivel. E considerada por alguns um inibidor modesto (16) e contrariamente por outros um fator facilitador que, ligando o ferro, diminuiria a tendēncia de formação de hidróxidos pouco solūveis no intestino(64).

CLYDESDALE (13), em ampla revisão sobre o tema, res salta a importáncia desses conceitos na escolha de uma for ma de ferro para fortificação de alimentos. Assim, pirofosfatos, ortofosfatos, hidrōxidos e ōxidos são relativamen te insolūveis em àgua, quando comparados com hidrōxidos e cloretos $(16)$.

Diversos trabalhos desenvolvidos sobre o assunto ${ }^{(38)}$ $(48)(49)(53)(66)(75)$ mostram que a biodisponibilidade de fer ro e de outros nutrientes é portanto o resultado de um con junto de fatores.

Assim, a biodisponibilidade de ferro de uma dieta depende da forma em que o elemento se apresenta, das intera ções que se processam no lümen intestinal e de variações ine rentes ao organismo.

0 estudo desses fatores, atravēs de métodos jā con sagrados é importante, como aponta STEKEL (76), na medida em que define a possibilidade de absorção de ferro por populações de países em desenvolvimento e explicam a alta incidéncia de ane 
mia nestas populações.

Um ponto de partida para possíveis modificações des se quadro é a caracterização dos alimentos mais consumidos em um paîs.

No Brasil, o inquérito feito em 1975 , publicado no ESTUDO NACIONAL DE DESPESA FAMILIAR (ENDEF) (25) è um documento oficial de que se dispõe para a sistematização desses es tudos.

Esse documento atesta a variedade dos häbitos ali mentares da população brasileira e a importāncia de se avaliar, por regiões, as dietas mais consumidas, e os alimentos que as compõem.

A determinação quantitativa do ferro aportado pela dieta, e a avaliação de sua biodisponibilidade, são passos essenciais na direção dessas metas, constituindo o objetivo geral de nosso trabalho.

Paralelamente aos estudos de biodisponibilidade desenvolvem-se as tēcnicas para sua determinação. Segundo HALL $B E R G(34)$, a escolha entre eles depende, em grande parte, de seu custo.

0 rato tem sido muito utilizado nos estudos de ab sorção e metabolismo do ferro (15)(27)(28)(41)(69)(80).

o rato anêmico è o modelo experimental utilizado na determinação da biodisponibilidade, pelo método chamado curativo (2), 
o parâmetro medido por esse método é o aumento da concentração de hemoglobina desses animais, quando alimenta dos com diferentes fontes de ferro que compõem as rações, a serem testadas. A restrição feita a esse método é a impossibilidade de extrapolar para seres humanos, os resultados obti $\operatorname{dos}(81)$.

Uma alternativa que surgiu para os estudos de bio disponibilidade foi a utilização de métodos "in vitro" como os descritos por NARASINGA RAO(47) e MILLER(51).

Baseiam-se, fundamentalmente, na simulação da diges tão do alimento ou dieta, seguida de uma diālise em membrana semì-permeàvel.

A porcentagem de ferro dialisado é, então, determinada e esse resultado segundo SCHRICKER(72) apresenta uma boa correlação com os métodos "in vivo" feitos em seres humanos. 
2. OBJETIVOS

Determinar a biodisponibilidade de ferro de dieta Regional de S.Paulo (com base no ENDEF), em ratos anêmicos.

Determinar a porcentagem de ferro dialisāvel nessa dieta pelo método "in vitro".

Comparar os resultados com os obtidos pelos mesmos métodos com dietas a base de caseĩna.

Fazer uma avaliação preliminar da adequação da dieta regional de S. Paulo em relação ao ferro. 
3. MATERIAL E METODOS

3.1 Preparação e anāilise das rações

\subsubsection{Material}

3.1.1.1 Ração à base de caseîna

Foram preparados dois tipos de ração à base de caseīna, seguindo as especificações do COMMITEE on Laboratory ANIMAL DIETS/NCR, cuja composição é descrita no Quadro 1.

QUADRO 1 - COMPOSIÇÃO DAS RAÇÕES A BASE DE CASEINA

\begin{tabular}{|c|c|c|}
\hline & $\begin{array}{c}\text { Ração de caseĩna } \\
\text { controle } \\
\%\end{array}$ & $\begin{array}{l}\text { Ração de caseĩna } \\
\text { "livre de ferro" }\end{array}$ \\
\hline Caseĩna & $20,0(12)$ & $20,0(12)$ \\
\hline DL-metionina & 0,2 & 0,2 \\
\hline Bitartarato de colina & 0,1 & 0,1 \\
\hline бleo de soja & 8,0 & 8,0 \\
\hline Mistura salina* & 3,5 & - \\
\hline Mistura salina isenta de ferro & - & 3,5 \\
\hline Mistura vitamīnica & 1,0 & 1,0 \\
\hline Celulose & 1,0 & 1,0 \\
\hline Sacarose & 10,0 & 9,0 \\
\hline Sacarose $+\mathrm{FeSO}_{4} 7 \mathrm{H}_{2} \mathrm{O}^{* \star}$ & - & 1,0 \\
\hline Amido de milho qsp & 100,0 & 100,0 \\
\hline
\end{tabular}

* a quantidade de ferro foi ajustada de forma a chegar na concentração presente na dieta regional.

** sempre que a concentração de ferro na cãseína foi maior do que 70ug/ $\mathrm{g}$, reduziu-se o teor de proteína na ração. 
Nos Quadros 2 e 3 , estão descritas as composiçções das misturas salina e vitaminica utilizadas nas rações à base de caseina.

QUADRO 2 - COMPOSIÇÃO DA MISTURA SALINA UTILIZADA NAS RAÇð̄ES $\bar{A}$ BASE DE CASEINA

\begin{tabular}{|lc|}
\hline \multicolumn{1}{|c|}{$\mathrm{Sa}$ is } & $\mathrm{g} / \mathrm{kg}$ \\
\hline $\mathrm{CaCO}_{3}$ & 367,80 \\
$\mathrm{KH}_{2} \mathrm{PO}_{4}$ & 500,00 \\
$\mathrm{MnSO}_{4} \cdot \mathrm{H}_{2} \mathrm{O}$ & 5,10 \\
$\mathrm{KCr}\left(\mathrm{SO}_{4}\right)_{2} \cdot 12 \mathrm{H}_{2} \mathrm{O}$ & 499,26 \\
$\mathrm{KIO}_{3}$ & 214,00 \\
$\mathrm{CuCO}_{3} \mathrm{Cu}(\mathrm{OH})_{2}$ & 221,11 \\
$\mathrm{MgO}^{2}$ & 40,32 \\
$\mathrm{ZnCO}_{3}(70-73 \% \mathrm{ZnO})$ & 1,60 \\
$\mathrm{NaCl}_{2} \mathrm{SO}_{4}$ & 74,00 \\
$\left.\mathrm{NaSeO}_{3} \cdot 5 \mathrm{H}_{2}\right) \mathrm{O}$ & 0,01 \\
\hline & \\
\hline
\end{tabular}



QUADRO 3 - COMPOSIÇAOO DA MISTURA VITAMINICA UTILIZADA NAS RAÇOES A BASE DE CASEINA

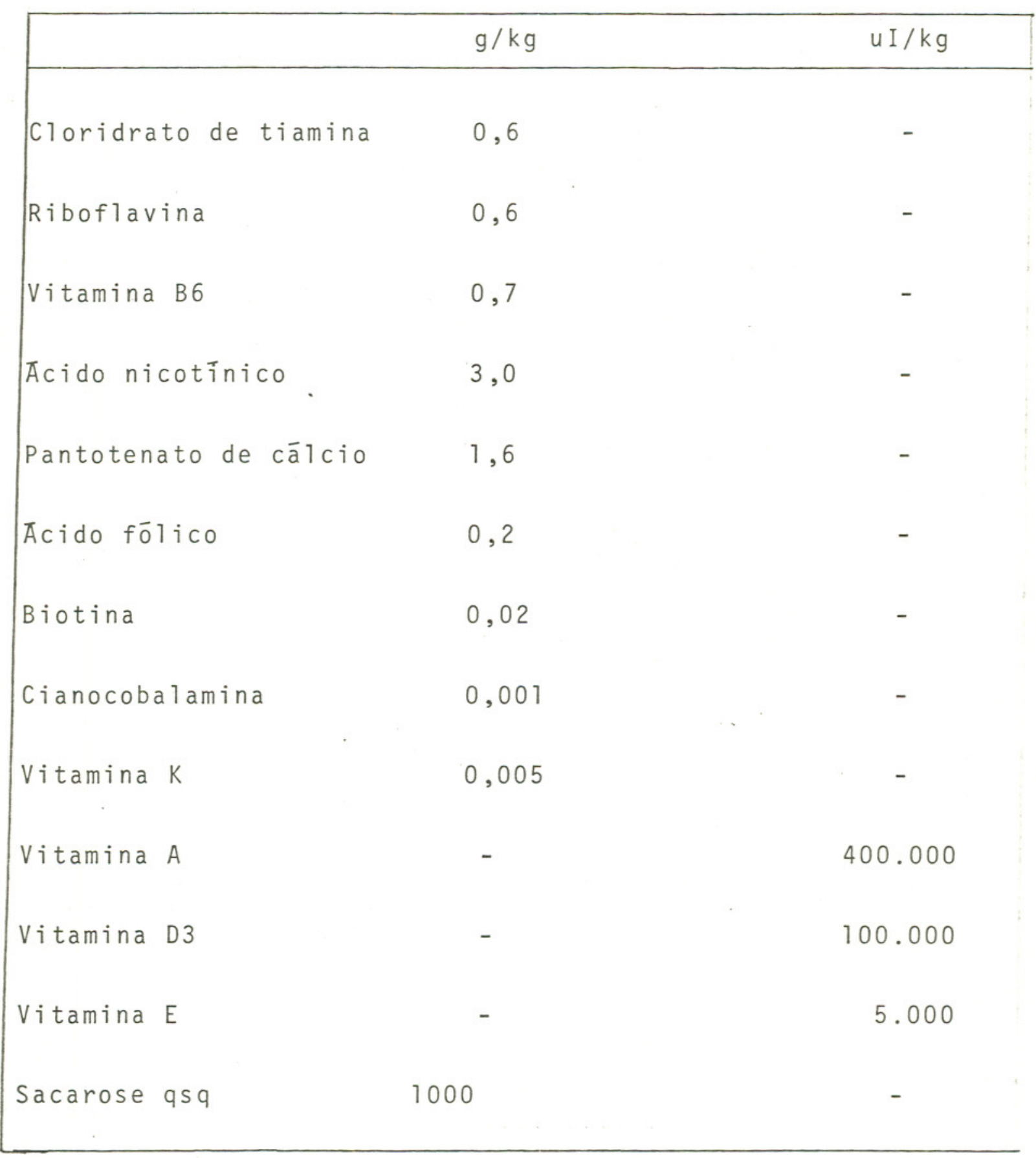


3.1.1.2 Ração à base de feijão

A ração à base de feijão foi formulada após a determinação da porcentagem de proteinna do feijão carioca cozido em autoclave, seco e moîdo.

o feijão,foi então colocado em porcentagem tal que fornecesse $20 \%$ de proteína.

A composição dessa ração consta do Quadro 4, abaixo.

QUADRO 4 - RAÇÃO A BASE DE FEIJÃO

\begin{tabular}{|lc|}
\hline \multicolumn{1}{|c|}{ Componentes } & $\%$ \\
\hline Feijão & 73,0 \\
oleo de milho & 8,0 \\
Celulose & 1,0 \\
Mistura salina* & 4,0 \\
Mistura vitaminica* & 1,0 \\
Metionina & 1,0 \\
Amido qsp & 100,0 \\
\hline
\end{tabular}

* as misturas salina e vitamínica têm a mesma composição das utilizadas nas rações de caseína controle (Quadros 2 e 3 ). 
3.1.1.3 Ração à base da dieta regional de São Paulo

A ração à base da dieta regional de São Paulo foi preparada com alimentos adquiridos em um supermercado 10cal.

Os alimentos que a compõem constam do Quadro 4. A formulação dessa dieta foi baseada nos dados fornecidos pe10 Estudo Nacional de Despesa Familiar (ENDEF-1978)(34).

De cada grupo de alimentos contantes da tabela do ENDEF foram escolhidos os que aportavam $75 \%$ ou mais de calorias do grupo. O déficit de calorias (25\% ou menos) foi coberto pelos mesmos alimentos na proporção em que se apresentam dentro do grupo.

QUADRO 5 - COMPOSIÇÃO PORCENTUAL DA DIETA REGIONAL DE SÃO PÁULO

\begin{tabular}{|lc|}
\hline Componentes & $\%$ \\
\hline $\begin{array}{l}\text { Cereais e derivados } \\
\text { arroz } \\
\text { pão }\end{array}$ & 20,4 \\
Raĩzes, tubērculos e similares & 8,0 \\
batata & \\
farinha de mandioca & 6,4 \\
\end{tabular}


continuação

\begin{tabular}{|c|c|}
\hline Componentes & $\%$ \\
\hline \multicolumn{2}{|l|}{ Leguminosas } \\
\hline feijão carioca & 4,7 \\
\hline \multicolumn{2}{|l|}{ Hortaliças folhosas } \\
\hline couve & 0,3 \\
\hline repolho & 0,3 \\
\hline \multicolumn{2}{|l|}{ Não-folthosos } \\
\hline tomate & 2,7 \\
\hline cebola & 1,6 \\
\hline abōbora & 0,7 \\
\hline abobrinha & 0,7 \\
\hline beterraba & 0,5 \\
\hline cenoura & 0,5 \\
\hline chuchu & 0,4 \\
\hline pepino & 0,4 \\
\hline pimentão & 0,4 \\
\hline \multicolumn{2}{|l|}{ Frutas } \\
\hline banana nanica & 2,9 \\
\hline laranja & 3,2 \\
\hline 1 imão & 3,2 \\
\hline$a b a c a x i$ & 2,1 \\
\hline maçã & 1,0 \\
\hline \multicolumn{2}{|l|}{ Carnes } \\
\hline boi & 4,8 \\
\hline porco & 0,8 \\
\hline frango & 3,2 \\
\hline salsicha & 1,1 \\
\hline
\end{tabular}


continuação

\begin{tabular}{|lc|}
\hline Componentes & $\%$ \\
\hline Ovos & 2,3 \\
ovo de galinha & \\
Leite & 14,0 \\
leite de vaca & \\
ס leos e gorduras & 3,2 \\
óleo de soja & 1,1 \\
banha de porco & \\
Açūcar e derivados & \\
açūcar de cana & \\
\hline
\end{tabular}

BIBLIOTECA

Faculdade de Ciências Farmacêuticas

Universidado de São Paulo 


\subsubsection{Métodos}

\subsubsection{Preparação das rações}

Os componentes da ração controle de caseína e de feijão foram misturados em homogeneizador de pás.

Os componentes sōilidos da ração de caseína 1ivre de ferro foram, em uma primeira etapa, misturadas manualmente. Em seguida essa mistura foi passada em peneira de plās tico e homogeneizada em moinho de bolas.

Foi acrescentado o óleo e repetiu-se o processo por mais quatro vezes.

Todos os acessōrios utilizados foram previamen te desmineralizados em banho de $\mathrm{HNO}_{3}$ a $20 \%$ e lavados com àgua desionizada.

$$
\text { Os alimentos componentes da dieta regional }
$$

(Quadro 4) foram preparados da maneira normalmente utilizada pela população e secos em estufa ventilada a 600 C.

Apōs a secagem, foram pulverizados em moinho de facas e misturados em homogeneizador de pás.

A ração pronta foi armazenada em recipiente de plástico e conservada a 40 C. 


\subsubsection{Determinação da composição centesimal das rações}

A composição centesimal das rações foi feita segundo os métodos preconizados pelo Instituto Adolfo Lutz(36) e pela ASSOCIATION OF OFFICIAL ANALYTICAL CHEMISTS(4). São os seguintes:

a) Umidade - gravimetria em estufa a 1050 C;

b) Fração cinza - gravimetria em mufla a 550̣C;

c) Nitrogēnio total - mētodo de micro Kjeldahl (utilizou-se o fator 6,25 para conversão a proteĩna);

d) Extrato etéreo - extração com éter etîlico p.a. em extrator de Soxhlet;

e) Fibra - método enzimātico(5).

A fração livre de nitrogēnio foi determinada por diferença. 
3.1.2.3 Determinação de minerais
a) Ferro total

As amostras das rações foram oxidadas em mufla a 550 c e solubilizadas com ácido nîtrico a $20 \%$.

A determinação de ferro foi feita por espectro fotometria de absorção atōmica, utilizando-se o equipamento PERKIN ELMER modelo 373, e lâmpada de catodo oco.

As condições de calibração foram as seguintes:

- comprimento de onda: $248,3 \mathrm{~nm}$;

- fenda: $0,2 \mathrm{~nm}$;

- mistura de gases: acetileno/ar;

- tipo de chama: oxidante.

0 padrão utilizado foi $\mathrm{FeCl}_{3} \operatorname{Merck}$ (Titrisol), numa faixa de concentração de 0,5 a $5 \mu \mathrm{g} / \mathrm{ml}$.

b) Ferro não hemînico

o ferro não hemínico foi determinado somente na ração à base da dieta regional de São Paulo, pelo método de Torrence( ${ }^{(79)}$ e Hallgren, modificado por Hallberg(33). 
c) Cāicio e fósforo

A determinação desses trēs componentes da dieta regional foi feita segundo as técnicas analîticas do Instituto Adolfo Lutz(36).

3.2 Repleção de hemoglobina em ratos anêmịcos

3.2.1 Material

3.2.1.1 Animais

Foram utilizados ratos (Rattus norvegicus), ma chos, da linhagem Wistar, recém-desmamados pesando de $45-50 \mathrm{~g}$ e de criação do Biotērio da Faculdade de Ciências Farmacêuticas da Universidade de São Paulo.

\subsubsection{Métodos}

3.2.2.1 Obtenção de ratos anēmicos (Fase I)

Os animais, alojados em gaiolas de aço inoxidā vel, foram alimentados com a ração à base de caseîna, com ba $\underline{i}$ 
xa concentração de ferro, por perīodos que variaram entre 35 e 45 dias, em quatro ensaios (no $1-4)$. Nos ensaios 1 e 2 os animais foram colocados em gaiolas individuais, e nos ensaios 3 e 4, 2 animais por gaiola.

A ração e a água (desionizada) foram fornecidas "ad libitum".

Em um grupo de 6 a 10 animais, escolhidos por sorteio, foi controlado o consumo de ração a cada trēs dias e o peso semanalmente.

Após o perīodo determinado, foram colhidas amostras de sangue através de corte feito na cauda dos animais, para a determinação da concentração da hemoglobina.

No segundo experimento, foram escolhidas aleatoriamente dez animais recém-desmamados para a determinaçãoda concentração inicial da hemoglobina do grupo. O sangue foi co Thido dos animais anestesiados, por punção cardíaca.

Ainda nesse experimento foi constituído um gru po controle alimentado com ração de caseína adequada quanto à concentração de ferro. 


\subsubsection{Repleção da hemoglobina (Fase II)}

Os animais anēmicos, obtidos na Fase I, foram agrupados segundo a concentração de hemoglobina no sangue, de forma a se obter o menor coeficiente de variação intra e intergrupos. 0 nūmero de animais, por grupo, foi de 6 a 10.

Foram testadas as rações à base da Dieta Regio nal de São Paulo, de feijão e de caseĩna com 70 e $35 \mu \mathrm{g} / \mathrm{g}$ de ferro, fornecidas "ad 1 ibitum" por períodos de 7 a 12 dias.

Após esse período, procedeu-se à coleta de san gue como jā descrito no item 3.2.2.1. No entanto, foram feitas também coletas de sangue em intervalos de 4 dias em pelo menos um dos grupos constituídos para cada ração testada.

A partir da diferença de peso e de concentração de hemoglobina, calculou-se a quantidade de ferro incorpo rado durante o período de repleção $(\Delta F e)$. Assume-se que o volume de sangue dos animais corresponde a $0,067 \%$ de seu peso corporal e que a porcentagem de ferro na hemoglobina è de $0,355 \%(39)$.

A porcentagem de ferro absorvido foi calculada pela relação entre $\Delta \mathrm{Fe}$ e quantidade de ferro consumido. 
3.3 Determinação da porcentagem de ferro dialisāvel das rações em estudo

\subsubsection{Material}

As amostras das rações à base de caseīna e da Dieta Regional de São Paulo foram acrescidas de água em quantidade correspondendo a 2,5 vezes o seu peso.

Apōs a homogeneização o pH foi levado para 2 com HCl $0,1 \mathrm{~N}$ e as amostras foram conservadas em congelador a -200 C.

\subsubsection{Método}

A porcentagem de ferro dialisāvel foi determinada pelo método "in vitro" descrito por Miller (47).

Para tanto,foi estabelecida a concentração de ferro não hemīnico de amostras da Dieta Regional de São Paulo, como descrito no item

A determinação radiomētrica da porcentagem de ferro dialisado foi feita somente nessa dieta. 0 traçador em- 
pregado foi $0{ }^{59} \mathrm{FeCl}_{3}$ (Amersham) com $100 \mu \mathrm{ci} / \mu \mathrm{g}$ de atividade específica.

As medidas de radioatividade foram feitas em contador sōilido de cintilações, de NaI (Tl) tipo poço acoplado a espectrōmetro (modelo nuclear Chicago). 


\section{RESULTADOS E DISCUSSÃO}

\subsection{Composição de Dieta Regional}

o objetivo primeiro de nosso trabalho é o de avaliar a biodisponibilidade de ferro em uma dieta que corresponda, 0 máximo possível, à consumida pela população de São Paulo.

Assim, partindo dos resultados do inquérito do EN-

DEF(25), preparamos essa dieta que, depois de seca, foi utili zada como ração experimental.

A avaliação de sua adequação, feita a partir da composição centesimal da ração (tabelas I e II), mostra-nos que essa dieta não satisfaz às necessidades energēticas diārias de adultos normais que, conforme as recomendações da FAO/OMS $(55)(56)$ corresponde a $3100 \mathrm{kcal}$ e $2300 \mathrm{kcal}$ para homens e mulheres, res pectivamente.

A ingestão diāria de $54 \mathrm{~g}$ de proteîna a partir da dieta está acima das recomendações, embora não esteja implîc $\underline{j}$ to que o aproveitamento da proteīna seja adequado. Uma avalia ção do valor biológico dessa proteîna não foi objetivo nosso. No entanto, vale ressaltar que a dieta formulada por nōs, com base nos dados do ENDEF, corresponde à media das dietas consumidas pela população do Estado. 
TABELA I - COMPOSIÇĀO CENTESIMAL DAS RAÇÖES Ā BASE DE DIETA REGIONAL DE SAOO PAULO (DRSP)

\begin{tabular}{|c|c|}
\hline Umidade & 6,2 \\
\hline Cinzas & 2,2 \\
\hline Proteīna & 11,7 \\
\hline Lipĩdeos & 11,8 \\
\hline Fibra & 6,3 \\
\hline Extrato livre de nitrogēnio & 61,8 \\
\hline Energia (kcal/g) & 4,00 \\
\hline Ferro $(\mathrm{g} / \mathrm{g})$ & 33 \\
\hline Cālcio (mg\%) & 257 \\
\hline Fósforo (mg\%) & 180 \\
\hline
\end{tabular}


TABELA II - COMPOSIÇÃO dA DiETA REgIONAL DE SÁO PAULO (DRSP) (1)

\begin{tabular}{|c|c|c|c|c|}
\hline \multirow{2}{*}{ Componentes } & \multicolumn{2}{|c|}{ Ingestão diāria } & \multicolumn{2}{|c|}{ Necessidades diärias $(3)$} \\
\hline & DRSP $(1)$ & $\operatorname{DRSP}(2)$ & Mulher adulta & Homem adulto \\
\hline Energia (kcal) & 1830 & 1529 & 2300 & 3100 \\
\hline Proteîna (g) & 54 & 46 & 41 & 49 \\
\hline Lipỉdeos (g) & 54 & 23 & $15-25$ & $15-25$ \\
\hline Carboidratos (g) & 282 & 285 & 285 & \\
\hline Minerais (g) & 10 & 11 & & \\
\hline Ferro (mg) & 15 & 12 & $14-28(4)$ & $5-9$ \\
\hline Cálcio (mg) & 388 & 313 & $400-500$ & $400-500$ \\
\hline Fōsforo (mg) & 823 & 1965 & 800 & 800 \\
\hline
\end{tabular}

(1) Para uma ingestão diāria média de $895 \mathrm{~g}$ segundo o ENDEF/1974.

(2) Dados reproduzidos de estudo feito com a dieta da população de renda menor do que 2 salārios mỉnimos $(<2 S M)(59)$.

(3) Segundo a FAO/OMS. (55)(56)

(4) Segundo a $\operatorname{RDA}(63)$ 
Segundo Campana(11) em sua anālise final de vārios in quéritos sobre o consumo de alimentos em diversas regiões brasileiras (ENDEF incluĩdo), hā uma relação evidente entre o nîvel sócio-econōmico e o consumo de energia e a qualidade da proteína ingerida pela população.

Quando comparamos pela tabela I a composição da dieta do Estado com a da população de baixa renda feita por Porto Dantas (58), observamos diferenças quantitativas no aporte diārio de nutrientes.

Especificamente quanto à ingestão diāria de ferro, podemos dizer que ambas estão no limite da adequação para a muTher adulta $(14-28 \mathrm{mg} / \mathrm{d})(34)$.

Sabemos que essas recomendações assumem uma absorção de $10 \%$ do ferro consumido. No entanto, dados obtidos no Progra ma de Prevenção de Deficiência de Ferro na América Latina( 1 ) revelam uma absorção de $3 \%$ a partir de uma dieta de arroz e feijão formulada com base no ENDEF. 0 mesmo valor foi obtido por Hallberg( 33$)$ com dieta semelhante. 
4.2 Padronização das condições de obtenção de ratos anēmicos

A composição centesimal das rações à base de case $\bar{i}-$ na com baixo teor de ferro, utilizadas nessa fase de depleção, e a da caseĩna com concentração de ferro adequada (usada como controle) constam da Tabela III. Devido ao alto teor de ferro presente na caseína e em outros componentes da ração, houve necessidade de se reduzir a concentração de proteína de $17 \%$ para $10 \%$ para se manter a concentração ao redor dos $15 \mu \mathrm{g} / \mathrm{g}$. Uma forma alternativa de indução de anemia seria o sangramento repetido dos animais (57). No entanto, a perda de proteina e de minerais ocasionada por esse processo seria uma agressão bioquỉmica que traria variāveis não controláveis ao ensaio.

Por outro lado, a anemia mais branda resultante da redução menos drástica no teor de ferro da ração cria um mode 10 experimental mais condizente com o grau de anemia por defi ciência de ferro, encontrado em uma população como a nossa.

A avaliação do crescimento dos animais alimentados com dietas com baixo teor de ferro $(14 \mu \mathrm{g} / \mathrm{g})$ mostra que essa redução não leva a uma alteração no ganho de peso, quando esses animais são comparados com o grupo alimentado com ração 
TABELA III - COMPOSIÇÃO CENTESIMAL DAS RAÇOES dE CASEINA COM BAiXO TEOR DE FERRO E DE CASEINA CONTROLE

\begin{tabular}{|c|c|c|c|c|c|}
\hline \multirow{2}{*}{$\begin{array}{l}\text { Ensaio nọ } \\
\text { Componentes }\end{array}$} & \multicolumn{4}{|c|}{ Caseina baixo teor } & \multirow{2}{*}{$\begin{array}{l}\text { Caseina } \\
\text { Controle }\end{array}$} \\
\hline & 1 & 2 & 3 & 4 & \\
\hline Umidade & 10,0 & 9,6 & 8,1 & 9,2 & 8,8 \\
\hline Cinzas & 2,8 & 2,4 & 3,1 & 3,0 & 2,6 \\
\hline Proteína & 17,2 & 10,8 & 10,5 & 17,0 & 10,0 \\
\hline Lipĩdeos & 8,0 & 8,0 & 8,0 & 8,3 & 9,0 \\
\hline Fibra* & 1,0 & 1,0 & 1,0 & 1,0 & 1,0 \\
\hline $\begin{array}{l}\text { Extrato livre } \\
\text { de nitrogênio }\end{array}$ & 61,0 & 68,2 & 69,3 & 61,5 & 68,6 \\
\hline Energia (kcal) & 3,85 & 3,88 & 3,91 & 3,89 & 3,95 \\
\hline Ferro (mg) & 14 & 19 & 16 & 19 & 32 \\
\hline
\end{tabular}

* Valores de formulação 
com teor de ferro adequado $(32 \mu \mathrm{g} / \mathrm{g})$. Contudo, houve uma dife rença significativa no coeficiente de eficácia protéica (CEP) que indica menor aproveitamento da caseína da ração com baixo teor de ferro (Tabela IV e Figura 1).

Esse dado não corresponde ao obtido por outros autores $(28)(73)$ em experimentos semelhantes. Nesse sentido, obser vou-se a partir de vārios ensaios que a redução de ferro nas rações não altera o ganho de peso e o consumo de ração.

Sendo assim, uma avaliação da proteĩna nessas condições deveria ser comprovada por meio de outros indices como o NPR e O CEA.

$\mathrm{Na}$ Tabela $\mathrm{V}$, em que se tem o valor de hemoglobina fi nal obtida em dois ensaios de depleção, observa-se que esses valores relacionam com o consumo diārio de ferro. Assim, partindo-se do valor de hemoglobina de $11,4 \mathrm{~g} / \mathrm{dl}$ obtido no inīcio do período de depleção, chegou-se a valores de 6,5 e $8,3 \mathrm{~g} / \mathrm{dl}$ para consumos diārios de 0,13 e $0,23 \mathrm{mg}$ de ferro,res pectivamente.

Dados obtidos por outros autores $(28)(29)(41)(44)(73)$ mostram a relação entre os teores de ferro (como $\mathrm{FeSO}_{4}$ ) na ra ção e a concentração de hemoglobina em ensaios de depleção fẹ tos em ratos, por periodos de $35 \mathrm{~d}$, e que podem ser resumidos conforme relação abaixo: 
TABELA IV - GANHO DE PESO E CONSUMO DE PROTEINA DE ANIMAis ALIMENTAdOS COM RAÇOES A BASE DE CASEINA COM BAIXO TEOR DE FERRO E CONTROLE, POR 28 DIAS

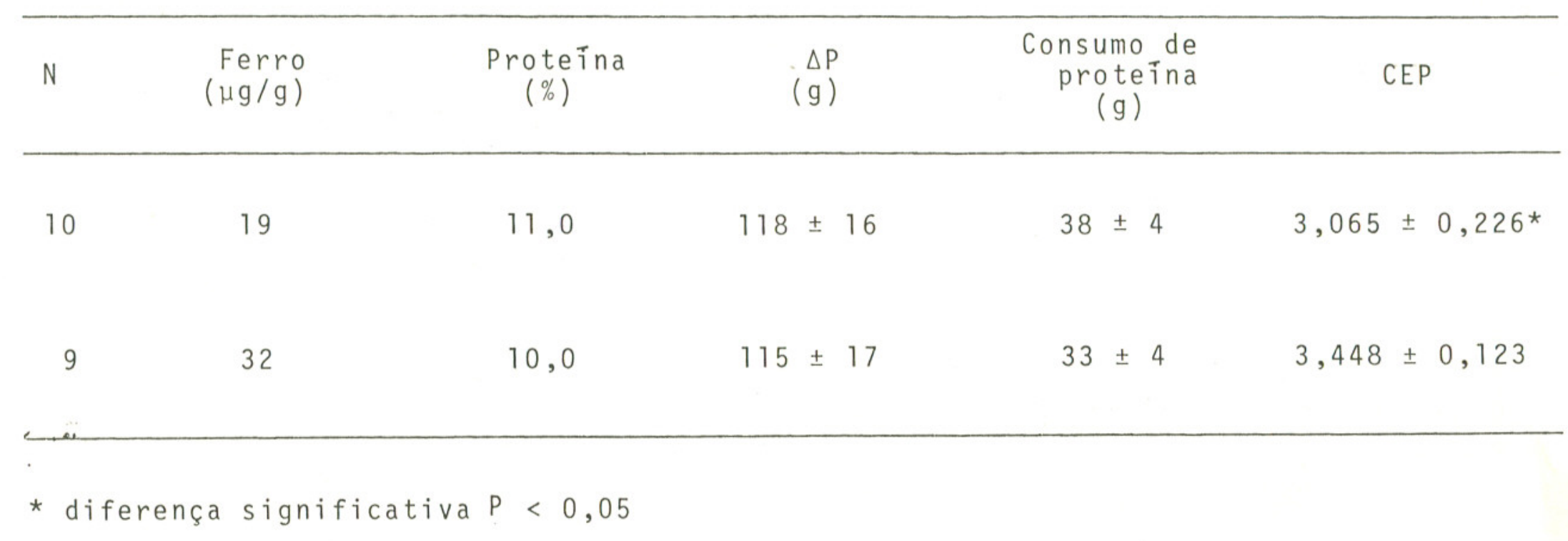




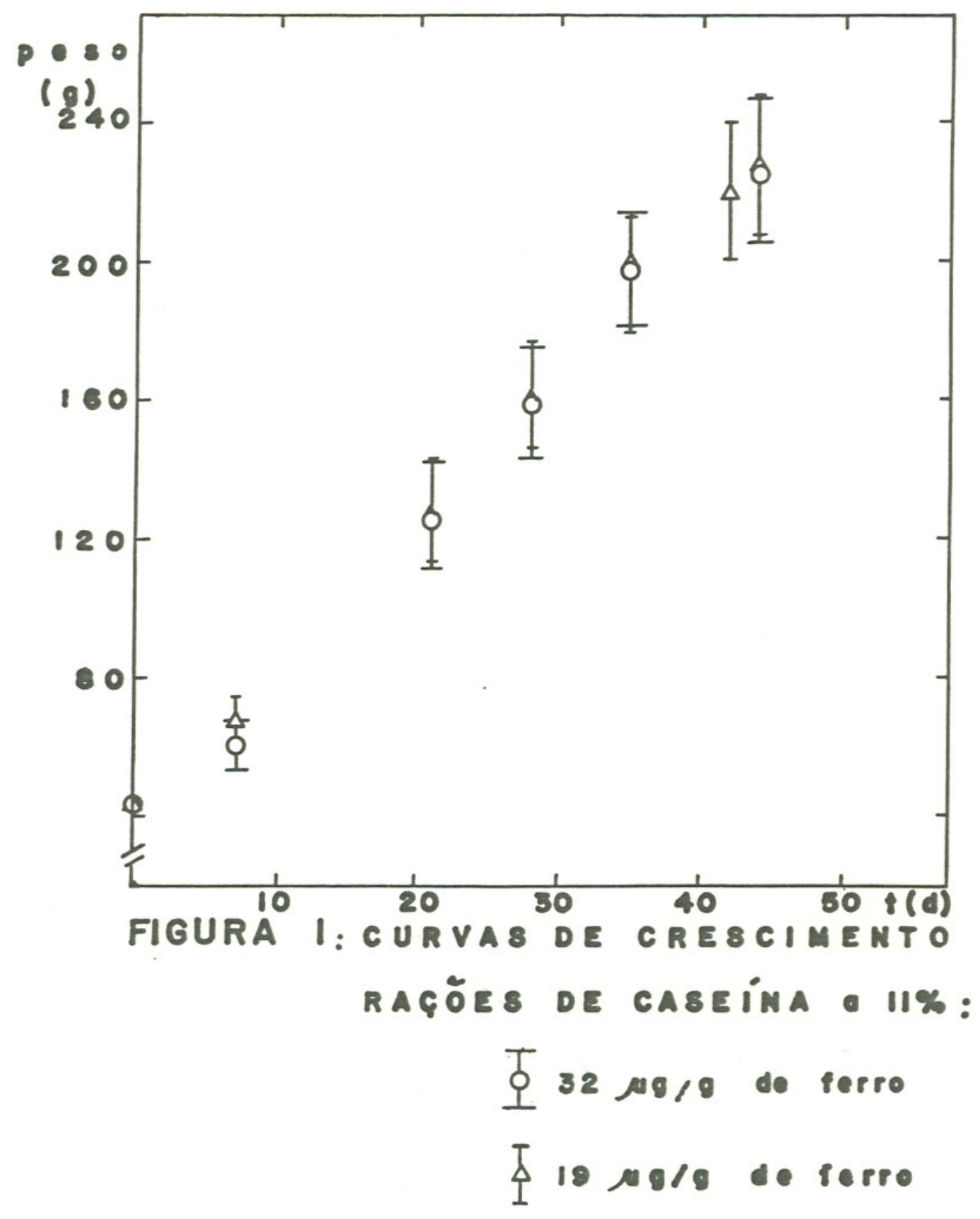


TABELA V - GANHO DE PESO, CONSUMO DE FERRO E CONCENTRAÇAO FINAL DE HEMOGLOBINA DE RATOS ALIMEN TADOS COM RAÇOES A BASE DE CASEINA COM BAIXO TEOR DE FERRO, E CASEINA CONTROLE DURANTE 35 a 45 DIAS.

\begin{tabular}{|c|c|c|c|c|c|c|c|c|}
\hline $\begin{array}{c}\text { Ensaio } \\
\text { nọ }\end{array}$ & $n$ & $\begin{array}{l}\text { Ferro } \\
(\mu \mathrm{g} / \mathrm{g})\end{array}$ & $\begin{array}{c}\Delta t \\
(\text { dias })\end{array}$ & $\begin{array}{l}\text { Consumo } \\
\text { de ferro } \\
\mathrm{mg} / \mathrm{d}\end{array}$ & $\begin{array}{l}\text { Peso } \\
\text { Inicial } \\
(\mathrm{g})\end{array}$ & $\begin{array}{c}\text { Peso } \\
\text { final } \\
(g)\end{array}$ & $\begin{array}{l}\Delta P \\
(g)\end{array}$ & $\begin{array}{l}\text { Hemoglobina } \\
\text { final } \\
(\mathrm{g} / \mathrm{d} 1)\end{array}$ \\
\hline 1 & 8 & 14 & 39 & $0,13 \pm 0,02$ & $46,4-3,1$ & $180,4 \pm 30,2$ & $134,4-29,4$ & $6,5 \pm 0,9$ \\
\hline 2 & 10 & 19 & 43 & $0,23 \pm 0,02$ & $43,6-1,7$ & $219,7 \pm 18,6$ & $176,2 \pm 19,4$ & $8,3-1,3$ \\
\hline * & & 32 & 43 & $0,38 \pm 0,03$ & $43,4-1,5$ & $221,8 \pm 19,4$ & $178,4-19,3$ & $12,7 \pm 0,6$ \\
\hline $3 * *$ & 7 & 16 & 41 & $0,18 \pm 0,01$ & $52,3 \pm 2,3$ & $185,4-25,0$ & $133,1 \pm 24,3$ & $11,1 \pm 1,0$ \\
\hline $4 * \star$ & 7 & 19 & 35 & $0,19 \pm 0,01$ & $52,5 \pm 3,9$ & $195,5-13,3$ & $143,0 \pm 11,4$ & $12,5 \pm 2,3$ \\
\hline
\end{tabular}

*0 valor médio de hemoglobina inicial no começo do experimento corresponde a $11,4 \pm 0,4 \mathrm{~g} / \mathrm{d} 1$ $(n=10)$

**Experimento feitos com dois animais por gaiola

$n$-corresponde ao número de gaiolas 


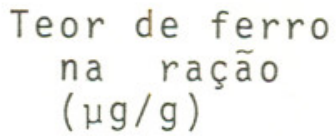

$4-7$

17

$>25$
Concentração final de

hemoglobina

$(g / d 1)$

5

9

13

A redução da concentração de hemoglobina dos animais alimentados com as rações com teores de ferro entre 14 e 20 $\mu \mathrm{g} / \mathrm{g}$ em relação ao controle é de cerca de $40 \%$.

E importante que se comente o fato de a média de con centração de hemoglobina do grupo controle $(12,7 \pm 0,6 \mathrm{~g} / \mathrm{d} 1)$ não atingir os valores normais para 0 rato de 50 dias $(15 \mathrm{~g} / \mathrm{dl})$.

Embora sabendo do cuidado que se deve ter com esse tipo de comparação (dadas as variações do método entre laboratōrios) esse dado sugere que os $32 \mathrm{mg} / \mathrm{kg}$ de ferro na ração estão aquēm das necessidades do rato.

Além desses ensaios, foram feitos mais dois, em que se utilizaram animais de maior peso (com $50 \mathrm{~g}$ ou mais) e com dois animais por gaiola. Nesses, apesar de o consumo médio diārio por gaiola ter sido de $0,18 \mathrm{mg}$ de ferro, obteve-se a concentração média de hemoglobina de 12,5 e $11,4 \mathrm{~g} / \mathrm{d} 1$, respec tivamente.

Uma explicação possīvel, fundamentada em dados da $1 \underline{j}$ teratura (86), para essa pouca redução na concentração de hemo globina desses animais seria a ingestão de fezes e, em conse 
qüência, uma absorção maior de ferro nesses dois grupos.

Por outro lado, o peso maior dos animais no inicio do período de depleção pode significar nîveis maiores de ferro de reserva o que dificultaria a redução da concentração de hemoglobina com as rações com concentração de ferro nos niveis utilizados.

Além desses 4 experimentos descritos, foi feito um outro no qual se modificou a composição da ração basal, aumen tando-se a concentração de sacarose e diminuindo-se a de amido, com base em experimentos que demonstram que a sacarose di minui a biodisponibilidade de ferro nessa substituição( 43 ). Es ses dados sugerem que animais de menor peso, colocados em gaiolas individuais, respondem melhor nesse período de depleção.

Nesse experimento tambēm lavou-se a caseĩna - que apresentava um teor de ferro de cerca de $65 \mu \mathrm{g} / \mathrm{g}$ - com uma solução de EDTA (ác. etileno diaminotetracético) a 1\%.

E importante comentar a importāncia de se determinar a concentração de ferro nos componentes da ração. Além da caseîna, o amido e a celulose tambēm apresentam teores altos $(40 \mu \mathrm{g} / \mathrm{g}$ e $100 \mu \mathrm{g} / \mathrm{g})$ e variāvel a cada lote.

Segundo Fritz(29) que padronizou o método de repleção da hemoglobina, o teor de 5 a $7 \mathrm{mg} / \mathrm{kg}$ nas rações é facilmente obtido com a utilização de caseĩna com concentrações de ferro da ordem de $9 \mathrm{mg} / \mathrm{kg}$. 
Ao final do perīodo de depleção, a média da concentrạ ção de hemoglobina desses animais chegou a $7 \mathrm{~g} / \mathrm{dl}$, para um con sumo médio de ferro de $0,130 \mathrm{mg} / \mathrm{d}$.

Entretanto, o ganho de peso foi de $78 \pm 7 \mathrm{~g}$, muito aba $\underline{i}$ xo dos valores dos outros experimentos. E possivel ter havido uma alteração a nîvel da mucosa intestinal, por excesso de que lante residual na caseîna. A outra possibilidade é uma altera ção na resposta desses animais provocada pela substituição do amido por sacarose, na dieta basal.

Assim, os dados de repleção da hemoglobina feita com esses animais, vão ser tratados à parte. 
4.3 Valor biológico do ferro em dietas

Os ensaios de repleção da hemoglobina em ratos anēmi cos são objeto de muita discussão, principalmente quanto ao desenho experimental e ao tratamento dos dados para se expres sar a absorção de ferro.

0 método preconizado pela $A O A C$ (22)(23) implica a utị lização de um grande nūmero de animajs anêmicos para a constị tuição dos vārios grupos correspondentes aos diferentes níveis de ferro da dieta controle.

Utilizamos o método sugerido por Mahoney(38) que tem a vantagem da simplicidade e que tem sido validado em diversos experimentos de avaliação de biodisponibilidade de ferro $(38)(42)(53)(56)(80)$ :

Esse mētodo apresenta ainda uma boa correlação segundo diversos autores, como descrito por Linder ${ }^{(56)}$ com os ensaios de absorção feitos em seres humanos.

Na Tabela VI estão os resultados da determinação da composição centesimal das rações testadas nessa fase de reple ção; a figura 2. indica a linearidade da resposta - concentração de hemoglobina em função do tempo a partir dos valores iniciais de $8 \mathrm{~g} / \mathrm{dl}$, e atestam a validade do ensaio.

Nos animais alimentados com as rações à base de feijão com $200 \mu \mathrm{g} / \mathrm{g}$ de ferro e de caseĩna com $70 \mu \mathrm{g} / \mathrm{g}$, a concen- 
TABELA VI - COMPOSIÇÃO CENTESIMAL DAS RAÇÕES UTILIZADAS NA FASE DE REPLEÇÃO DA HEMOGLOBINA.

\begin{tabular}{|c|c|c|c|c|c|}
\hline & \multirow[t]{2}{*}{ DRSP } & \multirow[t]{2}{*}{ Feijão } & \multicolumn{3}{|c|}{ Caseĩna } \\
\hline & & & 1 & 2 & 3 \\
\hline Umidade & 6,2 & 7,0 & 10,2 & 8,8 & 9,0 \\
\hline Cinzas & 2,2 & 3,4 & 2,7 & 2,6 & 3,1 \\
\hline Proteĩna & 11,7 & 16,6 & 18,0 & 10,0 & 12,5 \\
\hline Lipídios & 11,8 & 9,3 & 8,1 & 9,0 & 11,0 \\
\hline Fibra* & 6,3 & N.D.* & $1,0 * *$ & $1,0 * *$ & $1,0 * *$ \\
\hline \multicolumn{6}{|l|}{ Extrato Livre de } \\
\hline Nitrogênio & 61,8 & 63,7 & 60,0 & 68,6 & 63,4 \\
\hline Energia (kcal/g) & 4,00 & 4,05 & 3,85 & 3,95 & 4,03 \\
\hline Ferro $(\mu \mathrm{g} / \mathrm{g})$ & 33 & 200 & 70 & 25 & 32 \\
\hline
\end{tabular}

* não determinada

** valores de formulação

DRSP - Dieta Regional de S. Paulo 


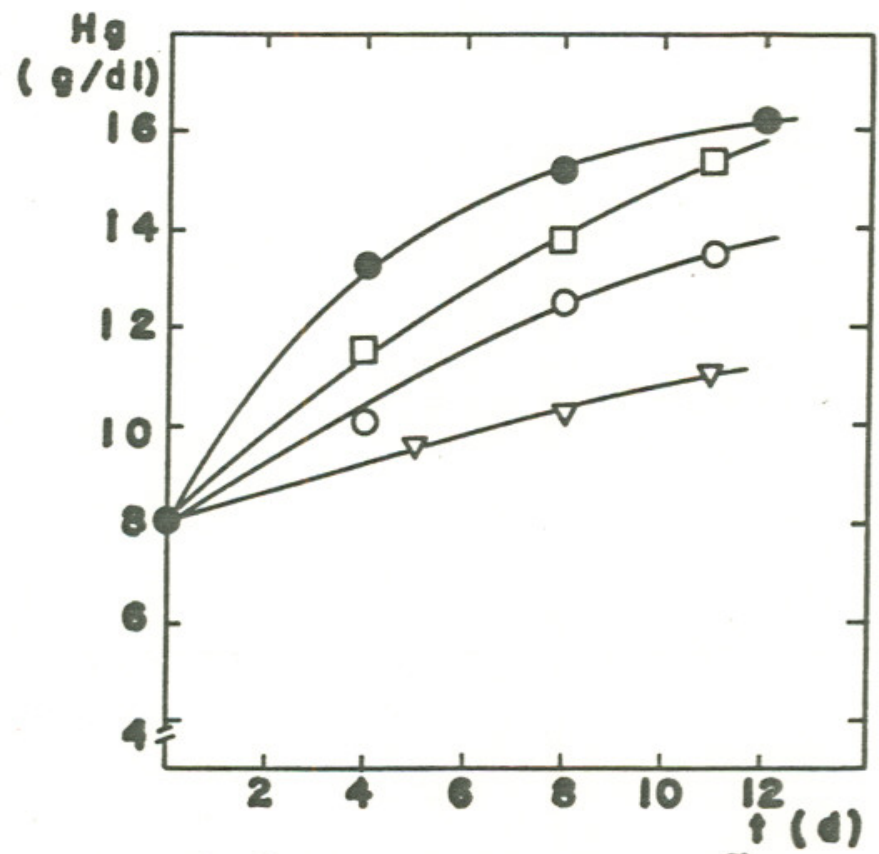

FIGURA 2: REPLEGÃO dO HEMOQLOEINA $F \in(/) g / g)$ - coseina 70 0 case ina 32 पFeijẫ 200 TDREP $\mathbf{3}$ 
tração de hemoglobina final chegou a valores de $16 \mathrm{~g} / \mathrm{dl}$, considerado normal para animais dessa idade.

Por outro lado, nos grupos alimentados com as rações de caseīna com 25 e $32 \mu g / g$ de ferro, e à base da dieta regio nal (DRSP), esse parāmetro hematológico não foi superior a $13,5 \mathrm{~g} / \mathrm{d} 1$.

Temos, descritos na Tabela VII, os resultados da absorção de ferro das trēs diferentes dietas que foram objeto de nosso trabalho.

Como mencionado anteriormente, os cálculos da eficiência de regeneração da hemoglobina foram feitos assumindo- se que o volume de sangue dos animais corresponde a $0.067 \%$ de seu peso, e que a proporção de ferro na hemoglobina é de $0,355 \%$.

Segundo Mahoney(38), esse tipo de procedimento elimi na as variações devidas a diferenças no consumo de ração, que não são consideradas quando se tem somente a variação da concentração de hemoglobina (Hg final - Hg inicial).

A partir dos dados da Tabela VII, podemos então dizer que a absorção de ferro da ração à base da dieta regional, por ratos anèmicos, é de $50 \%$. Fizemos a média dos três grupos uma vez que não houve diferenças entre elas.

Um dado interessante nessa primeira avaliação è que esse valor obtido não dependeu da concentração inicial de hemoglobina. Partindo de concentrações de 8 e de $10 \mathrm{~g} / \mathrm{dl}$, obti- 
TABELA VII - REPLEÇÃO DA HEMOGLOBINA EM RATOS ANEMICOS ALIMENTAdOS COM RAÇOES A BASE DE: DIETA REGIONAL, CASEINA E FEIJAOO.

\begin{tabular}{|c|c|c|c|c|c|c|c|}
\hline \multirow{2}{*}{$\begin{array}{c}\text { Fe na Ração } \\
\mu \mathrm{g} / \mathrm{g}\end{array}$} & \multicolumn{3}{|c|}{ Dieta Regional } & \multicolumn{3}{|c|}{ Caseina } & \multirow{2}{*}{$\begin{array}{l}\text { Feijão } \\
200\end{array}$} \\
\hline & 33 & 33 & 33 & 70 & 25 & 32 & \\
\hline \multicolumn{8}{|l|}{ Peso } \\
\hline Inicial (g) & $233 \pm 19$ & $188 \pm 21$ & $195-17$ & $194 \pm 21$ & $223 \pm 22$ & $188 \pm 25$ & $189 \pm 48$ \\
\hline \multicolumn{8}{|l|}{ Peso } \\
\hline Final (g) & $266 \pm 24$ & $246 \pm 30$ & $231 \pm 15$ & $250 \pm 17$ & $256 \pm 22$ & $247 \pm 22$ & $207 \pm 24$ \\
\hline$\Delta P \quad(g)$ & $33 \pm 8$ & $41 \pm 9$ & $36 \pm 3$ & $27 \pm 2$ & $33 \pm 7$ & $59 \pm 10$ & $18 \pm 3$ \\
\hline \multicolumn{8}{|l|}{$\mathrm{Hg}$ Inicial } \\
\hline$(g / d 1)$ & $8,3 \pm 1,4$ & $8,9 \pm 0,8$ & $10,3 \pm 0,8$ & $8,4 \pm 0,3$ & $8,3 \pm 1,4$ & $8,9 \pm 1,0$ & $8,1 \pm 0,5$ \\
\hline \multicolumn{8}{|l|}{$\mathrm{Hg} \mathrm{Final}$} \\
\hline$(g / d l)$ & $11,1 \pm 0,8$ & $11,7 \pm 1,6$ & $12,6 \pm 1,2$ & $16,2 \pm 0,6$ & $13,5 \pm 1,1$ & $10,5 \pm 1,5$ & $16,9 \pm 0,6$ \\
\hline$\Delta \mathrm{Fe}$ & $2,4 \pm 0,2$ & $1,9 \pm 0,6$ & $2,2 \pm 0,6$ & $4,6 \pm 1,0$ & $3,8 \pm 0,5$ & $2,2 \pm 0,4$ & $4,7 \pm 0,4$ \\
\hline \multicolumn{8}{|l|}{ Consumo: } \\
\hline ração (g) & $168+19$ & $167 \pm 39$ & $160 \pm 23$ & $178 \pm 6$ & $165 \div 17$ & $127 \pm 9$ & $123 \pm 8$ \\
\hline ferro (mg) & $5,2 \pm 1,0$ & $5,5-1,2$ & $5,3 \pm 0,8$ & $12,5 \pm 0,3$ & $4,1 \pm 0,4$ & $4,0 \pm 0,3$ & $24,6-1,5$ \\
\hline proteỉna (g) & $20 \pm 2$ & $19 \pm 5$ & $19 \pm 3$ & $34 \pm 2$ & $16 \pm 2$ & $14 \pm 1$ & $21 \pm 1$ \\
\hline$\% A$ & $48 \pm 9$ & $52 \pm 8$ & $42 \pm 11$ & $46 \pm 2$ & $92 \pm 11$ & $54 \pm 12$ & $19 \pm 1$ \\
\hline$\Delta t(d)$ & 11 & 11 & 9 & 12 & 11 & 7 & 12 \\
\hline$n$ & 6 & 10 & 9 & 6 & 6 & 6 & 6 \\
\hline
\end{tabular}


vemos os mesmos resultados finais.

Esse dado é vālido para esses dois nīveis de hemoglo bina inicial, uma vez que quando se considera uma variação maior, a tendēncia é haver uma diminuição da porcentagem de absorção $(70)$.

Nessa fase, houve, portanto, uma linearidade tanto na variação de hemoglobina com o tempo e com o ferro consumido, como no ganho de peso com o tempo.

os resultados obtidos com as rações de caseîna exigem uma discussão mais detalhada.

A absorção de ferro dos animais alimentados com as rações de caseína com $70 \mu \mathrm{jg} / \mathrm{g}$ e $32 \mu \mathrm{g} / \mathrm{g}$ foi a mesma, de $50 \%$. Embora o período de repleção tenha tido diferente, a mesma fundamentação usada para a avaliação dos resultados obtidos com a dieta regional assegura-nos da validade da comparação.

Park (56) obteve em 2 ensaios semelhantes feitos com ratos anêmicos uma absorção de 58 e $62 \%$ de ferro como $\mathrm{FeSO}_{4}$, com rações à base de caseîna.

Esse autor demonstra a boa correlação encontrada entre o resultado desses ensaios e aqueles feitos em seres huma nos anêmicos, nos quais para as mesmas fontes de proteîna e de ferro a absorção foi da ordem de $50 \%$

Uma questão deve ser colocada quando se avalia o resultado de $90 \%$ de absorção em ratos alimentados com a dieta 
A comparação entre os dois grupos constituídos - caseīna (32 $\mathrm{gg} / \mathrm{g})$ e DRSP - é vālida, uma vez que podem ser considerados homogêneos.

Assim, a absorção de ferro das duas rações foi a mes ma e da ordem de $50 \%$. 
4.4 Determinação do ferro dialisāvel

0 método "in vitro"(46)(51) de determinação da biodisponibilidade de ferro é ūtil para uma avaliação preliminar, sendo indicativo da biodisponibilidade "relativa" do elemento presente em um alimento ou dieta.

os resultados obtidos na determinação do ferro dial $\underline{i}$ sāvel nas rações de caseĩna e regional constam do quadro 6 . Essa determinação foi feita pelos mētodos colorimétrico e radiomētrico somente para a dieta regional.

Entre os valores de 7,4 e 8,4 , não houve interferēn cia do pH final do dialisado, na porcentagem de ferro, determinada, nessa ração, pelo mētodo colorimétrico entre 4,3 e $4,9 \%$.

Os valores encontrados para a dieta de caseĩna $(5,2$ e $5,6 \%$ ) foram significativamente mais altos do que os obti dos com a dieta regional.

A razão provāvel è que, embora com a mesma composição quĩmica, as dietas apresentaram diferenças qualitativas de componentes como carboidratos, gorduras e sais inorgānicos.

cook $(17)$, em ensaio feito "in vivo", comparou a bio disponibilidade de ferro de uma dieta padrão, com a de uma die ta semi-sintética, tendo a mesma composição química.

Verificou que, mesmo acrescentando a esta, quantida- 
QUADRO 6. - Ferro dialisável na dieta regional de S.Paulo e na de caseĩna $\left(^{*}\right)$

\begin{tabular}{|c|c|c|c|}
\hline \multirow{3}{*}{$\mathrm{pH}$} & \multicolumn{2}{|c|}{ Dieta Regional $(* *)$} & Dieta de Caseīna(***) \\
\hline & Método & Método & Mē todo \\
\hline & Colorimētrico & Radiométrico & Colorimétrico \\
\hline 7,4 & $4,27 \pm 0,40^{a}$ & $3,69 \pm 0,16^{b}$ & $5,22 \pm 0,30^{c}$ \\
\hline 7,5 & $4,87 \pm 0,40^{a}$ & & \\
\hline 7,6 & $4,38 \pm 0,20^{a}$ & & \\
\hline 8,4 & $4,37 \pm 0,38^{a}$ & & $5,60 \pm 0,20^{c}$ \\
\hline
\end{tabular}

${ }^{(*)}$ Médias de trēs determinações. Valores com o mesmo subs crito não são diferentes estatisticamente $(p<0,01)$

$\left({ }^{*}\right)^{*}, 1 \mu \mathrm{g} / \mathrm{g}$ de ferro não hemīnico.

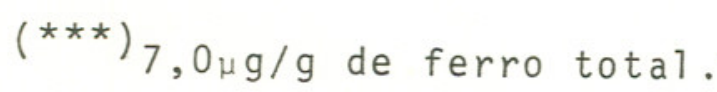


de caseina com $25 \mu \mathrm{g} / \mathrm{g}$ de ferro e 10\% de proteĩna.

Os efeitos da quantidade de proteína da dieta na absorção de ferro não hemínico, especialmente da alteração mode rada desses teores, não são muito bem definidos.

Sabe-se que a deprivação severa da proteína diminui a velocidade de eritroporese e, a partir daî, a absorção de ferro.

Miller(42) não constatou nenhum efeito mensurāvel na repleção da hemoglobina de ratos anêmicos quando alterou de 12 para $8 \%$ a concentração de proteĩna das rações de caseína. Assim, o teor de $10 \%$ de proteína dessa ração, mais baixo que a dos outros grupos provavelmente não é o fator res ponsāvel pelo aumento da absorção de ferro observado nesse grupo.

Por outro lado, a concentração de ferro nessa ração, de $25 \mathrm{\mu g} / \mathrm{g}$, está no 1 imite da adequação para o rato(14)(52).

A produção de proteĩnas heme pode ser restringida com ingestões de ferro abaixo desse valor(73).

No experimento com a ração basal em que se substituiu o amido por sacarose e se lavou previamente a caseína com solução de EDTA a 1\%, obteve-se um grau acentuado de anemia, expressa por concentrações médias de hemoglobina da ordem de $6 \mathrm{~g} / \mathrm{dl}$ nos grupos formados para o ensaio de repleção.

0 resultado desse ensaio feito com animais cuja ane mia foi provocada nas condições citadas constam da Tabela VIII. 
TABELA VIII - REPLEÇAOO DA HEMOGLOBINA EM RATOS ANEMICOS ALIMENTADOS COM RAÇOES A BASE DE DIETA REGIONAL.

\begin{tabular}{|c|c|c|c|c|c|c|}
\hline & \multicolumn{3}{|c|}{$\begin{array}{l}\text { Regional } \\
(35 \mu \mathrm{g} / \mathrm{g})\end{array}$} & \multicolumn{3}{|c|}{$\begin{array}{l}\text { Caseīna } \\
(32 \mu \mathrm{g} / \mathrm{g})\end{array}$} \\
\hline Peso inicial (g) & 134 & \pm & 14 & 120 & \pm & 12 \\
\hline Peso Final $(g)$ & 198 & \pm & 17 & 136 & \pm & 23 \\
\hline $\mathrm{Hg}$ inicial (g/dl) & 6,8 & \pm & 1,1 & 6,8 & \pm & 1,0 \\
\hline $\mathrm{Hg}$ final $\quad(g / d 1)$ & 10,1 & \pm & 1,5 & 7,8 & \pm & 0,5 \\
\hline$\Delta \mathrm{Fe} \quad(\mathrm{mg})$ & 2,6 & \pm & 0,2 & 2,32 & \pm & 0,3 \\
\hline \multicolumn{7}{|l|}{ Consumo } \\
\hline ração & 143 & \pm & 19 & 135 & \pm & 11 \\
\hline ferro & 5,0 & \pm & 0,7 & 4,3 & \pm & 0,4 \\
\hline$\% \quad A$ & 52 & \pm & 8 & 54 & \pm & 7 \\
\hline$\Delta t(d)$ & 7 & & & 7 & & \\
\hline$n$ & 8 & & & 7 & & \\
\hline
\end{tabular}


des de carne variando entre 25 e $100 \mathrm{~g}$, os valores de ferro ab sorvidos, embora aumentados, foram sempre menores do que os obtidos com a dieta padrão.

Assim, esse fato deve ser considerado quando se pensa na comparação entre as duas dietas em questäo.

A diferença encontrada na porcentagem de ferro, de terminada no dialisado pelos métodos radiométrico e colorimétrico $(4,5$ e $3,7 \%)$ respectivamente, estā de acordo com dados da 1 iteratura $(46)(70)$, sendo o mētodo radiométrico o de escoTha devido à sua maior precisão.

Sabe-se que os resultados de porcentagem de ferro dialisāvel determinada pelo mētodo "in vitro" apresentam boa correlação com os do mētodo "in vivo", feito com sēres humanos $(72)$.

Como nosso objetivo foi o de ter uma avaliação do que seria a absorção de ferro das suas dietas em indivĩduos normais, podemos dizer que houve uma diferença, embora pequena, da biodisponibilidade do ferro presente em ambas.

0 comentārio final é que os resultados obtidos suge rem que dieta formulada não apresenta diferença significativa na biodisponibilidade de ferro quando comparada à dieta de ca seỉna com o mesmo teor de ferro.

Quantitativamente, o ferro dessa dieta estā no 1 im te da adequação para a mulher em período fērtil, admitindo-se uma absorção de $10 \%$. 
No entanto, a biodisponibilidade desse ferro, deter minada pelo método "in vitro" correlaciona-se, como jā men cionado, com o mētodo "in vivo", não sendo muito diferentes os valores determinados pelos dois.

Assim, fixando entre 3 e $5 \%$ a porcentagem de absorção do ferro dessa dieta, ela estaria inadequada quanto ao aporte de ferro disponível.

Esses dados são importantes para o estudo das poss $\underline{7}$ veis modificações dessa dieta que possam melhorar esse quadro. 
5. CONCLUSÖES

5.1 - Teores de ferro entre 14 e $19 \mathrm{mg} / \mathrm{g}$, na ração basal de caseína fornecida a ratos em fase de crescimento, levam a uma redução de $40 \%$ na concentração de hemoglobina desses animais, quando comparados aos valores do grupo controle $(12,7 \mathrm{~g} / \mathrm{dl}$ e $7 \mathrm{~g} / \mathrm{dl}$, respectivamente).

5.2 - A redução de ferro de 30 para $5 \mathrm{mg} / \mathrm{g}$ em ração à base de caseina a $11 \%$ diminui o aproveitamento da proteīna por ratos em fase de crescimento, medido pelo coeficiente de eficācia protēica.

5.3 - Em ratos anêmicos, a biodisponibilidade de ferro de uma ração à base da dieta regional de São Paulo, formu lada a partir dos dados do ENDEF, è de $50 \%$ e igual à de ferro (como $\mathrm{FeSO}_{4}$ ) de uma dieta de caseína com a mesma composição centesimal .

5.4 - A porcentagem de ferro dialisāvel da ração à base de dieta regional é de $4,5 \%$; o valor para a dieta de caseīna é de $5,4 \%$; esses valores diferem significativa mente. 
5.5 - A concentração de ferro da dieta formulada com base no Estudo Nacional de Despesa Familiar (ENDEF) estā no lị mite da adequação do nutriente segundo a FAO/OMS. 


\section{6 - REFERENCIAS BIBLIOGRAFICAS}

01. ACOSTA, A.; AMAR, M.; CORNBLUth-SZARFARC, S.C.; DILlMAN, E.; FOSIL, M.; BIACHI, R.G.; GREBE, G.; HERTRAMPF, E.; KREMENCHUZKY, S.; LAYRISSE, M.; MARTINEZ-TORRES, C.; MORON, C; PIZATTO, F.; REYNAFARJE, C.; STEKEL, A.; VILLAVICENCIO, D.; ZUNIGA, H. - Iron absorption from typical Latin America diets. Am. J. Clin. Nutr., Bethesda, $39=953-962,1984$.

02. AMINE, E.K.; HEGSTED, D.M. - Biological assessment of available iron in food products J. Agri-Food. Chem., Washington, 22 (3): 470-476, 1974.

03. araújo, R.l.; araúdo, M.B.D.g.; Machado, R.D.P.; braga, A.A.; LEITE, B.V.; OLIVEIRA, J.R. - Evaluation of a program to overcome vitamin $A$ and iron deficiencies in areas of poverty in Minas Gerais, Brazil. Arch. Latino Am- Nutr $=$ Caracas, $37=9-22,1987$.

04. Association of Official Analytical Chemists official Methods of Analysis l4ed. Arlington, 1984, $1141 \mathrm{p}$.

* De acordo com as normas preconizadas pela associação Brasileira de Normas Técnicas (ABNT). As abreviaturas seguem o Chemical Abstracts Service Source Index (CASSI), 1985. 
05. ASP, G.N.; JOHANSSON, C.G.; HALLMER, H.; SILJESTROM, H. Rapid enzymatic assay of insoluble and soluble dietary fibre. J. Agric. Food Chem., Berkeley, $31=$ $476-482,1983$.

06. BAKER, S.J.; DEMAYER, E.M. - Nutritional anemia: its understanding and control with special reference to the work of the would Health organization. Am. J. Clin Nutr., Bethesda, 32: 368-417, 1979.

07. BERNER, L.A., MILLER, D.D. - Effects of dietary proteins on iron bioavailability - A review Food. Chem., Washington, $18=47-69,1985$.

08. BeUtler, E.; FAIRbanks, V.F. - The effects of iron deficiency, In: JACOBS, A., WORWOOD, M., Iron in biochemistry and Medicine II, London, Academic Press, 1980 , p. 393-425.

09. BRESSANI, R. - Deficiencias Minerales en America Latina, en produccion animal y en alimentos basicos Arch- Latinoam. de Nutrición, Caracas, $32: 16-23,1982$.

10. BRUNe, M.; MAGNUSSON, B.; PERSSON, H.; HALlberg, L. - Iron losses in sweat. Am-J.Clin-Nutr. Bethesda, $43: 438-443,1986$. 
11. CALlEnder, S.T. - The intestinal mucosa and iron absorption. Br_Med_Bul1 ., Edinbrugh $23(3): 263-265,1967$.

12. CAMPANA, A.O.; BURINI, R.C.; ANSElmo, M.A.C. - Population surveys in Brazil: data on energy and protein intakes and on energy and protein intakes and on anthropometric measurements of adult people. World-Rev-Nutr.Diet.., New York, 52: 209-234, 1987.

13. Clydesdale, F.M. - Physicochemical determinants of iron bioavailability. Food.Tech., Chicago, 37 (10): $133-138,1983$.

14. COMMITEE ON LABORATORY ANIMAL DIETS/ASSEMBLY OF LIFE SCIENCES NATIONAL RESEARCH COUNCIL. Control diets in laboratory animal experimentation Nutr-Abstr-Rev., Slough, $49: 413-419,1973$.

15. CONRAD, M.E.; PARMLEy, R.T.; OSTERLOH, K. - Small intestinal regulation of iron absorption in the rat. J.Lab.Clin.Med., St Louis, $110: 418-426,1987$.

16. COOK, J.D. - Determinants of nonheme iron absorption in man. Food-Tech., Chicago, 37 (10): 124-126, 1983. 
17. COOK, J.D.; MONSEN, E.R. - Food iron absorption. I. Use of a semisynthetic diet to study absorption of nonheme iron. Am-J_Clin-Nutr-, Bethesdar $28: 1289-1295,1975$.

18. COX, T.M.; PETERS, T.J. - The kinetics of iron uptake "in vitro" by human duodenal mucosa: studies in normal subjects. J.Physiol , London, $289: 469-479,1979$.

19. CROSBY, W.H. - Iron deficiency anemia in a nutritionally complex situation. Am-J_Clin-Nutr., Bethesda, $32: 715-716,1979$.

20. DAUIES, N.T. - Anti-nutrient factors affecting mineral utilization. Proc _Nutr _ Soc., London, 38: $121-128,1979$.

21. FOSSI, M, ; MENDEZ-CASTEllano, H.; JAFFE , W.G. ; MARTINEZ-TORRES, C.; LEETS, I.; TAYLOR, P., LAYRISSE, M. - Perfil hematologico y absorción del hierro de dietas que consume la poblacion de estrato socioeconomico bajo de los Estados de Venezuela. Arch-Lat inoam.Nutr., Caracas, $37: 23-35,1987$.

22. FRITZ, J.C.; PLA, G.W.; HARRISON, B.N.; CLARK, G.A Estimation of the bioavailability of iron. J. Ass.off.Anal-Chem., Washington, 58 : $902-905,1975$. 
23. FRITZ, J.C.; PLA, G.W.; HARRISON, B.N.; CLARK, G.A. Collaborative study of the rat hemoglobin repletion test for bioavailability of iron. J.Assoc.off.Anal. Chem., Washington, 57: 513-517, 1977.

24. FRITZ, J.C.; PLA, G.W. ; HARRISON, B.N.; CLARK, G.A.; SMITH, E.A. - Measurement of the bioavailability of iron using the hemoglobin repletion test. J.Ass.off.Anal. Chem., Washington, 61: 709-714, 1978.

25. FUNDAÇAO INSTITUTO BRASILEIRO E GEOGRAFIA E ESTATISTICA (FIBGE). Estudo Nacional de despesa familiar. Consumo Alimentar Antropometria. Região II São Paulo. Região IV Minas Gerais e Espririto Santo. Rio de Janeiro, 1977, 109p.

26. GRIVETTI, L.E. - Cultural Nutrition: anthropological and geographical themes. Ann-Rev-Nutr., Palo Alto, 1: $47-68,1981$.

27. GRUDEN, D. - Iron metabolism in rats from the fifth Iell the twenty-first day of life. Nutr-Rep-Int.., Los Altos, 28: 473-479, 1983.

28. GRUDEN, N. - The effect of iron dose on iron absorption in neonatal and weanling rats. Nutr-Rep.Int., Los Altos, 33: 693-699, 1986. 
29. hagler, L.; ASKeW, E.W.; Neville, J.R.; MEllk, P.W.; COppers, R.I., LOWDER, J.F. - Influence of dietary iron deficiency on hemoglobin, myoglobin, their respective reductases and skeletal muscle mitochondrial respiration. Am-J.Clin-Nutr - Bethesda, 34: 2169-2177, 1981.

30. HALLBERG, L. - Food Iron absorption, In: CoOK, J.D., Iron, N. York, Churchill Livengstone Inc., 1980, p. $116-133$.

31. Hallberg, L. - Iron In: Olson, R.E. et al., eds. Present knowledge in Nutrition 5 ed, Washington, Nutrition Foundation, 1984. p. 459-478.

32. Hallberg, L. - Bioavailable nutrient density: a new concept applied in the interpretation of food iron absorption data. Am.J.Clin.Nutr., Bethesda, 34: 2242-2247, 1981 .

33. hallberg. L., BJORN-RASMUSSEN, E.; ROSSANDER, L.; SUWANiK, R.; PLEE HACHINDA, R.; TUNTAWIROON, M. - Iron absorption from some Asian meals containing contamination iron. Am_J_Clin-Nutr., Bethesda, 37: 272-277, 1983 
34. HALlBeRG, L.; ROSSANDER, L. - Improvement of iron nutrition in developing countries: comparison of adding meat, soy protein, ascorbic acid, citric acid and ferrous sulphate on iron absorption from a simple Latin American-type of meal An.J.C1 in.Nutr., Bethesda, 39: 577-583, 1984.

35. HERBERT, V. - Recommended dietary intakes (RDI) of iron in humans. Am-J.Clin.Nutr., Bethesda, 45: $679-686,1987$.

36. INStituto ADOLFo LUTZ - Normas Analrticas do Instituto Adolfo Lutz, 3a. ed., São Paulo, 1985. Vl, 533p.

37. LINDER, M.C.; MUARO, H.N. - The mechanism of iron absorption and its regulation. Fed.Proc., Washington, 36 : 2017-2023, 1977 .

38. LYNCH, S.R., BEARD, J.L.; DASSENKO, S.A.; COOK J.D. - Iron absorption from legumes in humans. Ans.J.clin. Nutr., Bethesda, 40:42-47, 1984.

39. MAHONEY, A.W.; WITTAKER, P., FARMER, B.R., HENDRICKS, D.G. Iron bioavailability in an anemic rat model: effect of food restriction. Nutr-Rep.Intern., Los Altos, 31 (2): 457-462, 1985. 
40. MAY, P.M.; WILliANS, D.R. - The inorganic chemistry of iron metabolism, I: JACOBS, A.; WORWOOD, M.; Iron in biochemistry and Medicine II, London, Academic Press, 1980 .

41. MILleR, J. - Assessment of dietary iron availability by rat hemoglobin repletion assay. Nutr-Rep-Intern. Los Altos, 26 (6): 993-1005, 1982.

42. MILLER, J. - Effect of feed restriction on rate of hemoglobin regeneration in anemic rats. Nutr-RepIntern, Los Altos, 75 (3): 305-309, 1977.

43. MILLER, J. - Some effects of dietary protein on growth and iron metabolism in anemic rats. Nutr-Rep-Intern. Los Altos, 27 (3): 1187-1197, 1983.

44. Miller, J.; LANDES, D.R. - Effects of starch sucrose and glucose on iron absorption by anemic rats. Nutr - Rep - Intern., Los Altos, 14 (1): 7-11, 1976 .

45. MilleR, J.; LANDES, D.R. - Modification of iron and copper metabolism by dietary starch and glucose in rats. Nutr-Rep - Intern., Los Altos, 13 (2): 187-195, 1976. 
46. MILLER, D.D.; SCHRICKER, B.R. - In vitro estimation of food iron bioavailability in Nutritional Bioavailability of iron. ACS Symp.Ser. No 23. Constance Kies, Ed., 1982.

47. MILlER, D.D.; SCHRICKER, B.R.; RASMUSSEN, R.R.; VAN CAMPEN, An in vitro method for estimation of iron availability from meals. D. Am-J.Clin-Nutr., Bethesda, 34: 2248-2256, 1981 .

48. MORRIS, E.R. - An overview of current information on bioavailability of dietary iron to humans Fed_Proc ., Washington, 42: 1716-1720, 1983.

49. MORK, T.A.; LYNCH, S.R.; COOK, J.D. - Inhibition of food iron absorption by coffee. Am.J.C1 in.Nutr., Bethesda, $37: 416-420,1983$.

50. NARASINGA RAO, B.S. - Physiology of iron absorption and supplementation. Brit. Med. Bul1.., Edinbrugh, 37: 25-30, 1981 .

51. NARASINGA RAO, B.S.; PRABHAVATHI, T. - An in vitro method for predicting the biovailability of iron from foods. Am.J.Clin.Nutr., Bethesda, 31, 169-175, 1978 
52. Nutrient Requirements of Laboratory rat. In Nutrient rd

Requirements of Laboratory Animals, 3 ed. The National Academic of Sciences, Washington, D.C. 1978: p. 7-37 [Report no. 10].

53. NOJEIN, S.J.; CLydesdale, F.M. - Effect of pH and ascorbic acid on iron valence in model systems and in foods. J.Foof.Sci - 46: 606-611, 1981.

54. OLSZON, E.; ISAKSSON, B.; NORRBY, A.; SOLVELL, L. - Food iron absorption in iron deficiency Am-J.Clin-Nutr., Bethesda, 31: 106-111, 1978.

55. ORGANization mundial DE LA SAlud - Comité de Expertos. Los oligoelementos en la nutrición humana, Genebra, 1973. 71 p./ Série de Informes Técnicos, no. 532/.

56. ORGANIZACION MUNDIAL DE LA SALUd. Comité de Expertos. Necessidades de energia y de proternas. Genebra, 1985, 220p./ Série de Informes Técnicos, no. 724/.

57. PARK, Y.W.; MAHONEY, A.W.; CONFORTH, D.P. COLlingE, S.K.; HENDRICKS, D.G. - Biovailability to anemic rats of iron from fresh, cooked or nitrosylated hemoglobin and myoglobin. J.Nutr., Philadelphia, 113: 680-687, 1983. 
58. POLlack, S.; GEORge, J.N.; REBA, R.C.; KAUfMan, R.M.; CROsby, W.H. - The absorption of nonferrous metals in iron deficiences. J.Clin.Invest., New York, 44: $1470-1473,1965$.

59. PORTO DANTAS, R. - Brodisponibilidade de zinco em dieta Regional de Säo Paulo. São Paulo 1987. 109 p. Tese-Mestrado - Faculdade de Ciências Farmacêuticas da USP.

60. RAFFIN, S.B., WOO, C.H.; ROOST, K.T.; PRICE, D.C., SCHMID, R. - Intestinal absorption of hemoglobin iron - heme cleavage by mucosal heme oxygenase. J.Clin.Invest., New York, 54: 1344-1352, 1974.

61. RANGER, C.R.; NEALE, R.J. - Iron availability from soy, meat and soy/meat samples in anemic rats with and without prevention of coprophagy. J.Food-Sci., Chicago, $49: 585-589,1985$.

62. RANHOTRA, G.S.; GELROTH, J.A.; TORRENCE, F.A.; BOCK, M.A.; WINTERRINGER, G.L. - Iranian flat breads; relative biovaibility of iron. Cereal-Chem. St. Bet Paul, 58 (5): 471-474, 1981 .

63. RECOMMENDED DIETARY ALLOWANCES 9ed. Washington National Academy of Sciences, 1980, 185p. 
64. REINHOLD, J.G.; GARCIA, S.; GARZON, P. - Binding of iron by fiber of wheat and maize. Am-J.Clin-Nutr., Bethesda, 34: 1384-1391, 1981.

65. RONCADA, M.J.; SZARFARC, S.C. - Hipovitaminose A e anemia ferropriva em gestante de duas comunidades do Vale do Ribeira (Estado de São Paulo, Brazil). Rev. Saúde Púb1.. São Paulo, 9: 99-106, 1975.

66. ROSENBERG, I.H.; SOLOMONS, N.W. - Biological availability of minerals and trace elements a nutritional overview. Am-J_Clin.Nutr., Bethesda, 35: 781-782, 1982 .

67. ROSENMUND, A.; GERBER, S.; HUEBERS, H.; FINCH, C. Regulation of iron absorption and storage iron turnover. Blood, New York, 56 (1): 30-37, 1980.

68. SANFORD, P.A. - Inhibition of intestinal absorption Br - Med. Bu11 ., Edinburgh, $23: 270-274,1967$.

69. SAUIN, M.A.; COOK, J.D. - Mucosal iron transport by rat intestine. Blood, New York, 56: 1029-1035, 1980 . 
70. SCHRICKER, B.R.; MILLER, D.D. - In vitro estimation of relative iron availability in breads and meals containig different forms of fortification iron. J.Food.Sci.., Chicago, $47: 723-727,1982$.

71. SCHRICKER, B.R.; MILLER, D.D.; VAN CAMPEN, D. - Effects of iron status and soy protein on iron absorption by rats. J.Nutr., Philadelphia, 113:995-1001, 1983.

72. SCHRICKER, B.R.; MILLER, D.D.; RASMUSSEN, R.R.; VAN CAMPEN, D. - A comparison of in vivo and in vitro methods for determining availability of iron from meals. Am.J.Clin.Nutr., Bethesda, 34: 2257-2263, 1981 .

73. Sigulem, D.M.; TUDisCo, E.S.; GOLDENBERG, P.; ATHAide, M.M.M. ; VAISMAN, E. - Anemia ferropriva em crianças do município de São Paulo. Rev-Salide Públ., São Paulo, 12: 168-178, 1978.

74. SIIMES, M.A.; REFINO, C.; DALlMAN, P.R. - Manifestation of iron deficiency at various levels of dietary iron intake. Am-J_Clin-Nutr., Bethesda, 33= 570-574, 1980 .

75. SMITH, K.T. - Effects of chemical environment on iron bioavailability measurements. Food Tech, Chicago, 37, (10): 115-120, 1983. 
76. STEKEL, A. - Prevention of iron deficiency, In: STEKel, A., Iron nutritition in infancy and childhood.., New York, Raven Press, 1984, p. 179-194.

77. Stekel, A.; Amar, M., Calvo, E.; Chadud, P., hertranpf, E.; Llaguno, S.; Olivares, M.; PIZARRo, F. - Nutritional significance of interactions between iron and food components. Arch-Lat inam-Nutr., Caracas, $23(1): 33-41,1983$.

78. SZAR FARC, S.C. - Anemia ferropriva em populações da região sul do Estado de São Paulo. Rev-Saíde Públ.. São Paulo, 6: 125-133, 1972.

79. TORRANCE, J.D.; BOTH WELL, T.H. - A simple technique for measuring storage iron concentrations in formalinised liver samples S.Afr.J.Med.Sci., Johannesburgh, 33:9-11, 1968 .

80. VALBERG, S.; TAYLOR, K.B.; WITTS, L.J. - The effect of iron deficiency on the stomach of the rat. Brit.J. Nutr., London, 15: 473-480, 1961.

81. VAN CAMPEN, D.R. - Iron biovailability techniques: an overview. Food Tech., Chicago, 37: 127-132, 1983.

82. VAN CAMPEN, D.R.; WELCH, R.M. - Availability to rats of iron from spinach: effects of oxalic acid. J.Nutr., Philadelphia, $110=1618-1621,1980$. 
83. WEINTRAUB, L.R.; WEINSTEIN, M.B.; HUSER, H.; RAFAL, S. Absorption of hemoglobin iron: the role of a heme splitting substance in the intestinal mucosa. J.C1 in.Invest. , New York, 47: 531-539, 1968.

84. WhEBY, M.S.; SUTTLE, G.E.; FORD, K.T. - Intestinal absorption of hemoglobin iron. Gastroenterology, New York, 58: 647-654, 1970.

85. WRIGGLES WORTH, J.M.; BAUM, H. - The biochemical functions of iron. In: JACOBS, A.; WORWOOD, M., Iron in biochemistry and medicine, II London, Academic Press, 1980, p. 29-86. 
Foi feito um estudo de determinação da biodisponib $\underline{i}$ lidade de ferro em dieta regional de São Paulo, formulada com base no Estudo Nacional de Despesa Familiar (ENDEF).

Para tanto, foram utilizados o método de repleção da hemoglobina em ratos anêmicos e o método "in vitro" de determinação de ferro dialisāvel.

Paralelamente, avaliou-se as condições de obtenção de anemia em ratos. Concluiu-se que teores de 14 a $19 \mathrm{mg} / \mathrm{g}$ de ferro numa ração à base de caseîna levam a uma redução de cer ca de $40 \%$ (del2,7g/dl para $7 \mathrm{~g} / \mathrm{d} 1$ ) da concentração de hemoglobina dos animais em perīodos de 35 a 40 dias.

A biodisponibilidade de ferro, da dieta regional, pa ra ratos anêmicos é de $50 \%$ e igual à da caseīna com a mesma composição.

A porcentagem de ferro dialisāvel é maior na dieta à base de caseína do que na dieta à base de dieta regional $(4,5 \%$ e $5,4 \%$ respectivamente).

os resultados sugerem uma inadequação dessa dieta quanto ao aporte de ferro. 


\section{SUMMARY}

The hemoglobin repletion technique in anemic rats and an "in vitro" method were used to obtain data on iron bioavailability in a regional diet and in a diet based on $\mathrm{milk}$.

$$
\text { Previously, optimum condition for obtaining iron }
$$
deficiency anemia in rats were established.

Concentrations of iron from 14 to $19 \mathrm{mg} / \mathrm{g}$ in a basal casein diet led to a reduction of about $40 \%$ in hemoglobin concentration in a 35 days assay.

The percentage of bioavailable iron in both regional and casein diets for anemic rats was similar and averaged $50 \%$.

The percentage of dialysable iron in the casein diet was greater than in regional diet (5.4\% compared to $4.5 \%)$.

The results suggest an inadequaly of the regional diet related to iron. 